\title{
Influence on Confident Personality of College Students with Early Left-behind Experiences and Peer Counseling
}

\author{
Hu Wen Gan Xiaorong \\ Gannan Medical University, Ganzhou, Jiangxi, China, 341000
}

\begin{abstract}
Left-behind experience has obvious influence on the formation of college students' confident personality, which has both negative and positive effects. On the basis of understanding the connotation of confident personality and its development, the impact of left-behind experience on college students is analyzed in this paper, and then the effect and measures of peer counseling on eliminating negative influence and promoting positive influence are discussed, which provide reference recommendations for the development of college students' confident personality with left-behind experiences.

Key words: college students left - behind experience; confident personality; influence; peer counseling

From the age division, the so-called the students with left-behind experience should be born in the 1990s. Left-behind children refer to the children who stay in their hometowns, only to live with their parents or other relatives, because their parents go out to work. [1] Obviously, college students with the left-behind experience because of their childhood left-behind experience, a considerable part of which is bound to have obvious obstacles and shortcomings in the development of confident personality and mental health growth. Family is the basic unit of society, the family is social environment that is contacted by children early and importantly [2] and parents are undoubtedly an important factor, so if parents from their homes can bring the psychological impact to children which will always be extended to their youth. It is necessary and urgent to strengthen the psychological counseling for the undergraduates who have the experience of staying in their home, which is related to personal family happiness and social harmony. For the pursuit of counseling effect, the use of peer
\end{abstract}


counseling will become the main way to explore the psychological counseling for college students.

\section{The connotation and impact of confident personality}

1, the concept of confident personality

Personality is the sum of various psychological characteristics, and a relatively stable organizational structure of a variety of psychological characteristics, at different times and places, it affects a person's thoughts, feelings and behavior. Confident personality is related to confident, which is highlight and integration of the psychological characteristics. Confident is a kind of the psychological consciousness and psychological state of positive and effective expression of self-worth, self-respect, self-understanding, so a person's confident personality is a reflection of a person's ability to successfully complete an activity of with confidence and psychological characteristics, moreover, it reflects the positive and effective attitudes, tendencies, and choices in thinking and action not only affect the individual's learning, communication, employment, competition, innovation, achievements and behavior in varying degrees, but also contribute to the development of a stable structure of psychological consciousness and mental state. It will also show a significantly difference of personality, temperament and ability among people.

2 , the formation and development of confident personality

The development of confident personality requires confidence to build and accumulate. This process is not born, but gradually formed in life and social practice from successful experience, good outside information and positive attribution of success or failure. [3] Obviously, from the point of view of gradual formation and practice of confident personality, it is particularly important on a person's correct education, guidance and success or failure attribution. First of all, the formation and development of confident personality needs the most initial shape. Initial shaping refers to the child's confidence education, such as appreciation, encouragement, guidance and so on. Second, it needs continuous correction. Third, it needs to undergo spiral process. The formation and development of confident personality will not and should not be smooth, the real confidence must undergo wind and rain, to withstand setbacks in order to rock solid. Obviously, in the formation and development of confident personality, the child's parents must be the primary, important, or even decisive factors.

3 , factors affecting the development of confident personality

There are a lot of factors affecting the formation and development of confident personality, in addition to the natural personality of psychological characteristics, acquired and external impact will be very obvious. The development of individuals depends on many environmental factors, such as parents, family, economic situation, social environment, groups, culture, education and life experience. For college students with a left-behind experience, the impact of parental and family atmosphere will be basic and critical. On the 
family environment, it involves the cultural level, economic status, social status, groups and the home community environment and other factors, so in childhood left behind to enter the state of life, the impact of its confident personality will be great.

\section{The analysis of the impact of confident personality on college students with the left-behind experience}

1 , the significance of confident personality of college students with the leftbehind experience

According to the above discussion, the formation and development of the status quo of college students with left-behind experience is mainly caused by the separation of parents, so the change of family atmosphere is the main source. In the circumstances, the absence of parents affected their study and life and had a very deep concealment to their psychology, which will influence its personality longer, so the impact of personality development caused in the university age will show up. [4] Therefore, it is necessary to study the formation and development of the confident personality of the undergraduates. On one hand, through analyzing the confident personality of the undergraduates, we can discover the bad quality and prevent the distorted development of personality. On the other hand, we can cultivate their good quality and promote the healthy development of confident personality for socialist modernization and the cause and cultivating a good personality quality, qualified professional and technical personnel.

2 , the negative impact of confident personality of college students the leftbehind experience

(1) low self-esteem restrained psychology

The prominent feature of parent-child relationship lies in the close relationship. [5] But the deficiency of close relationship is very easy to cause leftbehind children unfamiliar with the family, cold for interpersonal relationships, and to have prevention and fear to contact with the passage of time, the relationship between the family. It will cause a high degree of mental health crisis, and further affect life interpersonal psychological barriers and decline the ability to face difficulties. Because of the impact of this experience, a considerable part of college students in the interpersonal relationship is not active, fear, panic or even resentment, which is certainly not caused by interaction with others, but its psychological inferiority too seriously.

(2) negative response to external things

Negative is a psychological and also an attitude, referring to mentality that a person faces other people or things tend to take the outside of inertia, avoid, reject or even opposition. Because of the long separation between parents and children, the support of left-behind children from the inside and outside of the family will be relatively small and the internal relatives can not be as caring and as their parents, and the external people are also far away from these children. The number of contacts and the degree of communication is different from the 
past, which resulted in left-behind children and external social people, things, contact methods, close to the degree of psychological differences and communication. Negative coping psychology and inferior self - esteem introverted psychology are opposite to each other in logical relationship. Their combined effect eventually leads to the weak and defective personality of such college students.

(3) easy to be sensitive and impulsed

Under normal circumstances, the undergraduates with left-behind experience will not have obvious abnormal performance, but in the case of external changes, they will show weird words and deeds compared with normal people, especially in the face of external injustice, impolite, bullying treatment, it is easy to reveal sensitive, extreme, impulsive characteristics. The separation of left-behind children and their parents is not only a lack of material care, but also a large degree of lack of spiritual care, and this love is a large part from each other's emotional exchange and psychological feedback. College students with the left-behind experience will show obvious psychological sensitivity that quickly turns into extreme emotions, triggering impulsive behavior.

3 , the positive influence of left - behind experience on college students' confident personality

(1) contribute to the formation of adaptive capacity

Definitely, left behind experience leaving this part of college students are not all negative effects, but there are positive effects, such as helping to adapt to the formation of capacity. Adaptability is the ability of a person to adapt to the difficulties, obstacles and challenges of all aspects of social life, and through individual efforts to solve an independent capacity. Adaptability does not only manifest itself as the external adaptation to the change of living environment and the pressure of social challenge, but also to the internal adaptation of emotional vacancy and psychological loneliness. As the left-behind children have to face long-term separation from their parents, a lot of life problems, learning problems and other social problems must be resolved, which will help them improve their practical ability. By using "Independent" way of life, these children must be formed to deal with problems alone thinking ability. Compared with the common college students, the adaptability and independence ability of college students with left-behind experience are more normal.

(2) help to enhance the ability to resist frustration

Anti - frustration ability is the ability of psychological response, emotional adjustment, spiritual support and active seeking to resolve tactics when individuals encounter frustration in reality. This is consistent with people 's psychological stability, strong spirit and firm will. As a result of the reality of family life, left-behind children need to face a variety of practical problems alone, and through their own efforts to solve these problems. After a failure, they sharpen the tolerance, adaptability and frustration, so that after entering college life, when they face new learning and life difficulties, they are more able to adapt to change, easier to accept the difficulties, and more patient than the average classmate. Even if it seems difficult, in the hearts of these students will be 
desalination. Therefore, the experience will help college students to strengthen the resistance to frustration and the formation of confident personality.

(3) help to improve self-struggle ability

Self-struggle is the ability of individuals to make self-establish goals, selfdeveloped struggle plan and adhere to the struggle to complete the process to achieve the goal of a capability. Self-struggle ability needs to be based on healthy psychology, with sound personality as the support, in particular the need for a good confident personality traction, in order to enable individual self-struggle ability to be rapidly improved. Naturally, self-struggle ability must also be based on sufficient self-excited process and practice. College students with the leftbehind experience have gone through training, they will have more clear objectives during the university, not only have reasonable expectations and hope for the future, but also through specific efforts to achieve the desired goal to change their status quo, their own future and their own life.

\section{Peer psychological counseling for the college students with left behind experience}

1, the connotation of peer counseling

Peer counseling is the psychological counseling model with a psychological counseling function. It refers to the age of those who need psychological assistance to students or friends for psychological guidance, comfort and support. [6] In general, peer counseling for counselors and counselors, because of the growth of the background and growth experience in common, is more likely to produce psychological resonance. In the university campus, there are many advantages, such as the broadness of counselors, the interactive nature of counseling activities, the affection of counseling relationships and the effectiveness of counseling results, of the peer counseling for the undergraduates who have left-behind experience.

2 , positive effect of peer psychological counseling

Left behind experience has the positive impact. In order to play a positive role, we must use the correct and effective psychological counseling process. The positive effect of peer counseling is that counseling is based on a similar lifestyle, similar values, and a common psychological orientation among friends or peers. First of all, peer counseling is conducive to the establishment of the counselors who need psychological environment and psychological atmosphere. Humanism believes that the success of peer counseling is not dependent on the level of counselor skills, but rather rely on counselor's attitude, that is, to be counseled to the truth, respect and accurate empathy is a good way to establish a good psychological atmosphere. Second, the peer counseling process is beneficial for the facilitator to provide similar groups of demonstration and impact for the counselor to imitate learning. Social learning theory suggests that the growth of individual hearts requires the correct influence of peer groups, and counselors can precisely provide the facilitator with such an exemplary correct impact. Moreover, 
peer counseling because of friendship or affection, initiative or spontaneous, extensive or interactive, also has the effectiveness that other methods can not be compared to.

3 , specific implementation of peer psychological counseling

First, college students with left-behind experience should be given special attention and respect. Schools should pay special attention to and love them, and should establish a special file for them in university as much as possible to understand and record their family situation, interpersonal relationships, personal psychology and individual development, etc., to pave the way for psychological education .

Second, students who have left-behind experience should be strengthened their sense of identity through peer counseling to develop their "selfunderstanding" mentality. So peer counseling is easier to create a mutual atmosphere of understanding. In face of the peer's respect and understanding, college students with the left-behind experience will deepen their understanding of their sensitive, fragile, low self-esteem and negative psychological symptoms will disappear.

Third, the college students who have left -behind experience should excavate the positive factors in their left-behind experience, and strengthen selfconfidence by self-value. The school should make full use of the characteristics of peer counseling in psychological education, to excavate the potential advantages of left-behind students, and to make them fully aware of the difficulties in adapting to the difficulties in staying behind, overcoming difficulties and indomitable spirit.

Fourth, students who have left-behind experience should communicate with the family to understand the other side of the left-behind life, in order to inspire them to forge ahead and improve their confidence. Schools should recognize and use this to help students and their families communicate to inspire them to improve their confidence, self-esteem, with their own efforts to return to their parents and society in order to shape its good confident personality, and to provide a strong quality support for the future life development.

\section{References:}

[1] [4] Wu Duoduo, Zhang Peiyun. There are Left-behind Experience of Personality Development and Optimization of College Students [J]. Journal of Education Journal of Jia Musi. 2013,05: 338-339

[2] Chen Zi, Lu Xi, He Cong, Lu Yang. Effects of Early Staying Experience on Personality of College Students [J]. Chinese Journal of Health Psychology. 2012,07: 1112-1119

[3] Liu Yulan. On the Development of Confident and Influencing Factors [OL]. http://blog.sina.com.cn/ 2013,10,05

[5] Cheng Xuhui. A Study on Personality Development of University Students with left behind experience [J]. Social Science .2015,11: 64-66 